\title{
References
}

1. «Oven» «Oborudovaniye dlya»/ http://www.owen.ru/21119386];

2. [Rukovodstvo po tekhnologii kombikormovoy produktsii s osnovami kormleniya zhivotnykh / V.A.Afanas'yev .: Voronezh, 2007. - S. 270-272;

3. Konspekt kursa lektsiy po distsipline "Teoriya avtomaticheskogo upravleniya" (chast' I) - Khobin V.A. OGAPT. Odessa - 2008 g;

4. Konspekt kursa lektsiy po distsipline"Spetsial'nyye razdely teorii upravleniya"-Khobin V.A.OGAPT.Odessa-2010 g;

5. Terekhov V.M. Sistemy upravleniya elektroprivodov: uchebnik. - M .: "Akademiya", 2005. - 301 s.;

6. Avtomatizirovannyy elektroprivod promyshlennykh ustanovok / G.B. Onishchenko, M.I. Aksenov, M.N. Zaritskiy i dr. Pod red. G.B. Onishchenko. - M .: RASKHN, 2001. - $520 \mathrm{~s}$;

7. Klyuchevoy V.I. Elektroprivod i avtomatizatsiya obshchepromyshlennykh mekhnizmov: Uchebnik dlya vuzov / V.I. Klyuchevoy, V.M. Terekhov. - M .: Energiya, 1980. - 360 s.

\section{ЗАСТОСУВАННЯ МОДИФІКОВАНОГО МЕТОДУ ПІНЧ-АНАЛІЗУ ДЛЯ ОПТИМІЗАЦЇ̈ СТРУКТУРИ УСТАНОВКИ ПЕРВИННОЇ ПЕРЕРОБКИ НАФТИ}

Application of the modified pinch-analysis method for optimization of installation structure of primary oil refining

Кривда В.І., к.т.н. ${ }^{1}$, Максимов М.В., д.т.н., проф. ${ }^{2}$ (Kryvda V., Maksimov M.,)

1,2 Одеський національний політехнічний університет, м. Одеса

${ }^{1}$ ORCID: 0000-0001-6647-1049 ${ }^{2}$ ORCID: 0000-0002-3292-3112

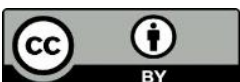

\section{Анотація}

Оптимальна структура установки первинної переробки нафти здатна створювати передумови для раціонального використання енергоресурсів на сучасному підприємстві. Крім того, така структура значно підвищує ефективність використання теплообмінного обладнання, що с безперечно важливим заходом 3 енергозбереження на виробництві по переробці нафтопродуктів. Заздалегідь правильно вибраний метод аналізу с запорукою чітких та вірних результатів при заданих початкових умовах. Напевно, що всі з відомих методів аналізу структур мають свої переваги, недоліки та особливості. В роботі пропонується посднати метод пінч-аналізу 3 методом ексергії-нетто. Така модифікація робить можливим використання переваг кожного 3 них для досягнення найкращих показників. Виконаний розрахунок параметричної чутливості функції 3 трьома змінними не виявив високої параметричної залежності приведених грошових та енергетичних витрат від заданих вихідних параметрів - температурного напору, вхідної температури сировини та кількості теплообмінних апаратів в установці первинної переробки нафти. Представлено загальну форму запису цільової функції задачі пошуку оптимальної структури установки первинної переробки нафти. Така цільова функція дозволяс комплексно аналізувати процес функціонування системи будь-якої технічної структури. Виявлено залежності приведених витрат в грошових та енергетичних одиницях від заданих вихідних параметрів. Визначено оптимальні значення цільових функцій і їх величини в крайніх точках області значень. Модифікований метод пінч-аналізу дозволяє порівнювати технікоекономічні показники 3 енергетичними результатами, які отримані після аналізу структури установки первинної переробки нафти.

\section{Abstract}

The optimum structure of installation of primary oil refining is capable to create pre-conditions for rational use of energy resources at the modern enterprise. Besides, such structure considerably increases efficiency of use of the 


\section{ДОПОВНЕННЯ \\ APPLICATION}

heat - exchange equipment. Undoubtedly it is an important event from energy saving on processing of oil products enterprise. Obviously correctly chosen method of the analysis is a guarantee of accurate and right results under the set initial conditions. For certain, all from known methods of the analysis of structures have their advantages, shortcomings and peculiarities. In this article it is offered to connect a pinch-analysis method with an net exergy method. Such modification allows to use advantages of each of them to achieve the best results. Fulfilled calculation of parametrical sensitivity of function with three variables didn't reveal high parametrical dependence of the given cash and power expenditures on the set initial parameters - a temperature pressure, entrance temperature of raw materials and number of heat - exchange devices in installation of primary oil refining. The general form of record of objective function of search of optimum structure of primary oil refining installation is presented. Such objective function allows to analyze in common the process of functioning the system of any technical structure. Dependences of the given expenses in monetary and power units on set initial parameters are revealed. Optimum values of objective functions and their size in extreme points of values area are defined. The modified method of the pinchanalysis allows to compare technical and economic indicators to the power results received after the analysis of structure of primary oil refining installation.

Ключові слова

Установка первинної переробки нафти, оптимальна структура, пінч-аналіз

Keywords

Installation of primary oil refining, optimum structure, pinch-analysis

Вступ

Підвищення ефективності використання теплообмінного обладнання на діючих нафтопереробних заводах $\epsilon$ важливим заходом по енергозбереженню. Економія первинних енергоресурсів на таких заводах дозволить знизити вартість кінцевого продукту на 10-20 \%. В якості критерію, що забезпечує ефективне використання енергоресурсів найчастіше приймається критерій мінімуму приведених витрат, що в умовах сучасної ринкової економіки $\epsilon$ актуальним.Будь-яка енергетична установка має свої, властиві саме їй, недоліки. Так, до основних недоліків установки первинної переробки нафти можна віднести такі: скидання високотемпературних газів в процесі конденсації легких фракцій світлого нафтопродукту через повітряні холодильники, витрата великої кількості вуглеводневого палива, як правило мазуту, для нагріву нафти в трубчастих печах. Вдосконалення структури установки первинної переробки нафти можна здійснити знаючи шляхи ліквідації виявлених недоліків. Їх можна усунути після проведення аналізу установки первинної переробки нафти. Такий аналіз дозволить виявити теплообмінне устаткування, в якому здійснюється нераціональне використання енергоресурсів.

Аналіз існуючих досліджень.

На практиці для аналізу енерготехнологічних установок [1] застосовуються такі методи як: метод пінч-аналізу [2-3], ексергетичний метод, метод ексергії-нетто і енергії-нетто, а також різноманітні техніко-економічні і термоекономічні методи. Кожен, з цих методів, має свої переваги, особливості і недоліки.

Метод пінч-аналізу дозволяє виконати інтеграцію технологічних процесів [4] на установці первинної переробки нафти, використовуючи в якості критерію оптимальності мінімум приведених грошових витрат на матеріальні ресурси. В свою чергу, метод ексергії-нетто, під час вибору оптимального варіанту, дозволяє врахувати коефіцієнт корисного використання палива при визначенні витрат енергії на різних об'єктах.

Мета роботи.

Представлення модифікованого методу пінч-аналізу для визначення оптимальної структури установки первинної переробки нафти.

Загальна характеристика модифікованого методу пінч-аналізу.

Використання пінч-аналізу дає змогу реконструювати структуру установки первинної переробки нафти шляхом зміни напрямів технологічних потоків, за умови максимального збереження кількості існуючих теплообмінних апаратів. Проте, цей метод не враховує величину енергетичних і матеріальних витрат на виготовлення i будівництво установки. Це можливо врахувати у разі використання методу енергії-нетто. Особливістю цього методу є складність в розрахунку енергетичної цінності вуглеводневих сумішей і складних хімічних складів, що знаходяться в рівноважному або у нерівноважному станах. На нафтопереробному заводі головними продуктами є складні вуглеводневі з’єднання різного структурного складу. Тому, виявляється доцільним використання комбінації розглянутих методів.

Приведені витрати в грошових одиницях мають вигляд 


\section{ДОПОВНЕННЯ \\ APPLICATION}

$$
\mathrm{B}_{\text {пр }}=\Pi К В+E \text {, у.о., }
$$

де ПКВ - приведені капітальні витрати на будівництво та виготовлення установки, у.о.;

$E$ - вартість витраченої енергії за рік, у.о..

Метод пінч-аналізу в потоковій теплоємності не враховує частку енергії, яка використовується на капітальне будівництво, виготовлення обладнання та спорудження установки первинної переробки нафти. Передбачається до потокової теплоємності додати перераховані сумарні витрати енергії, які пов'язані з виготовленням і будівництвом установки, як це запропоновано робити методом енергії-нетто. Тому, запропоновано другий варіант функції для пінч-аналізу, який базується на витратах енергії в системі. Приведені витрати в енергетичному еквіваленті визначаються за виразом

$$
E_{\text {пр }}=E_{\text {б }}+E_{\text {в }}, \mathrm{\kappa} \mathrm{BT} \text {, }
$$

де $E_{\text {б }}$ - приведені витрати енергії на будівництво і спорудження установки, кВт;

$E_{\text {в }}$ - витрачена енергія за поточний рік, кВт.

Таким чином, потокова теплоємність, яка враховує енергію-нетто при експлуатації теплообмінних апаратів визначається за виразом

$$
C P_{e}=\frac{H_{e}}{\Delta t}
$$

де $H_{e}=H+E_{e}$.

При обчисленні теплової потужності $H_{e}$ враховується як теплова потужність потоку $H$, так і енергіянетто $E_{e}$, витрачена при експлуатації теплообмінних апаратів.

Згідно з методом енергії-нетто енергія, витрачена на виготовлення установки первинної переробки нафти, визначається так:

$$
E=M \cdot e_{o}
$$

де $M$ - маса теплообмінних апаратів, кг;

$e$ - питома енергія, витрачена на виготовлення установки з даного виду матеріалу, МДж/кг.

Енергія, яка визначена за цим виразом враховує весь термін роботи установки, а потокова теплоємність розраховується на годинний інтервал часу, тому потрібно привести значення $E$ до годинного інтервалу часу:

$$
E_{e}=\frac{E}{T_{\mathrm{M}} \cdot N},
$$

де $T_{\text {м }}$ - максимальна кількість годин роботи установки на рік, год;

$N$ - кількість років роботи установки, що передбачається.

Проведення параметричної чутливості.

Проведення параметричної чутливості функції приведених витрат в грошових та в енергетичних одиницях дозволило виділити три основні аргументи, зміна яких впливає на функцію в цілому і відповідно на структуру обладнання установки первинної переробки нафти [1], а саме температурний напір $\Delta t$, вхідну температуру первинної сировини (нафти) $t_{\mathrm{H}}$ і кількість теплообмінних апаратів в установці $n_{\mathrm{TA}}$.

В якості прикладу (табл.1) наведено результати розрахунку параметричної чутливості у випадку, коли відбувається зміна трьох аргументів з кроком 1-20\%.

Таблиця 1 - Результати розрахунку параметричної чутливості в грошових одиницях

\begin{tabular}{|c|c|c|c|c|c|}
\hline Крок зміни аргументу & $\Delta t,{ }^{\circ} \mathrm{C}$ & $t_{\mathrm{H}},{ }^{\circ} \mathrm{C}$ & $n_{T A}$, шт. & В, тис. у.о. & Похибка, $\%$ \\
\hline $1 \%$ & 40,4 & 22,2 & 18 & 7,10 & $0 \%$ \\
\hline $5 \%$ & 42,4 & 23,3 & 19 & 7,12 & $0,28 \%$ \\
\hline $10 \%$ & 46,7 & 25,7 & 21 & 7,18 & $1,13 \%$ \\
\hline $15 \%$ & 53,7 & 29,5 & 24 & 7,26 & $2,25 \%$ \\
\hline $20 \%$ & 64,4 & 35,4 & 29 & 7,35 & $3,52 \%$ \\
\hline
\end{tabular}

В цілому виявлено такі результати: дослідження аргументу $\Delta t$, який змінюється на $20 \%$ призводить до зміни функцій на $3,1 \% ; t_{\text {н }}$ на $2,5 \%$, а зміна $n_{\mathrm{TA}}$ на $1,7 \%$. Зміна інших аргументів суттєво не впливає на значення 


\section{ДОПОВНЕННЯ}

APPLICATION

функції в цілому. Похибка функції приведених витрат, виражена в грошових одиницях, складала $\delta \mathrm{B}_{\text {пр }}=2 \%$, а в енергетичному еквіваленті $-\delta E_{\text {пр }}=1 \%$.

Оптимізація структури установки первинної переробки нафти.

Для визначення оптимальної структури установки первинної переробки нафти запропоновано функцію $F$, аргументами якої є температурний напір $\Delta t$, вхідна температура первинної сировини (нафти) $t_{\mathrm{H}}$ та кількість теплообмінних апаратів в установці $N_{\mathrm{TA}}$ :

$$
F\left(\Delta t, t_{\mathrm{H}}, n_{T A}\right)=K\left(n_{T A}, t_{\mathrm{H}}\right)+E(\Delta t)
$$

де $K\left(n_{T A}, t_{\mathrm{H}}\right)$ - приведені капітальні витрати на будівництво та виготовлення установки первинної переробки нафти;

$E(\Delta t)$ - витрати енергії за рік експлуатації.

При цьому задача оптимізації функції трьох змінних має наступний вигляд:

$$
F\left(\Delta t, t_{\mathrm{H}}, n_{T A}\right) \rightarrow \min _{\Delta t \in \Delta T, t_{\mathrm{H}} \in T_{\mathrm{H}}, n_{T A} \in N_{T A}} .
$$

Рішення поставленої оптимізаційної задачі дає можливість визначити величину приведених витрат при оптимальних значеннях температурного напору, температури вхідної сировини і кількості теплообмінних апаратів. Залежність приведених витрат в грошових та енергетичних одиницях від цих параметрів в області пінча наведено на рис. 1.

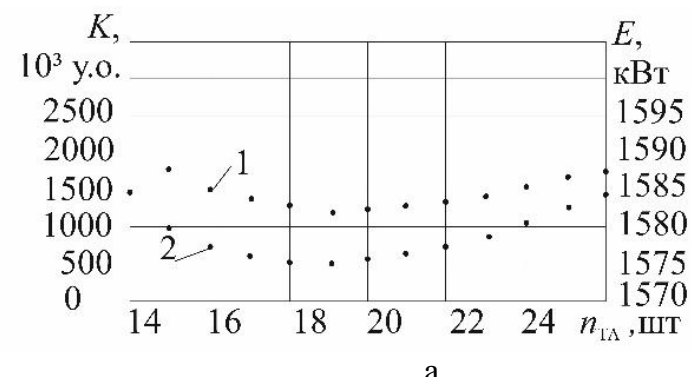

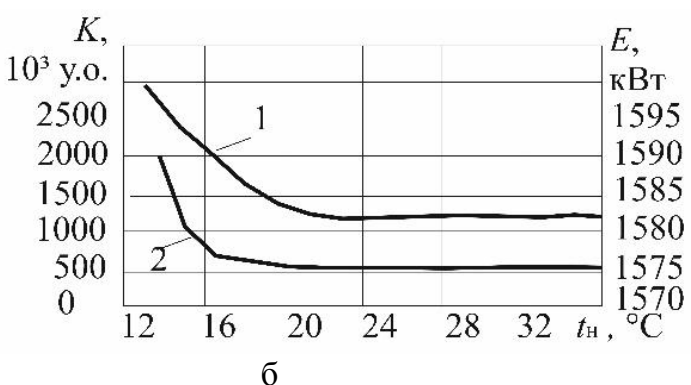

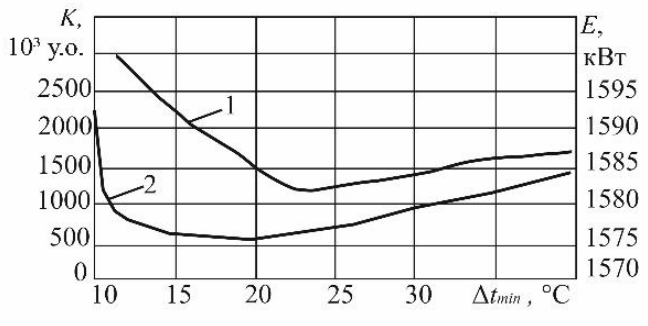

Рис. 1 - Залежність приведених витрат (1) та витрат енергії (2) в області пінча: а - від кількості теплообмінних апаратів; б - від вхідної температури; в - від температурного напору

В крайніх точках області значень цільова функція приведених витрат в грошових одиницях

$F \equiv B_{\text {пр }}$
приймає значення $\left.\mathrm{B}_{\text {пр }}\right|_{\Delta t_{\min }=10^{\circ} \mathrm{C}}=3000$ тис.у.о, $\left.\quad \mathrm{B}_{\text {пр }}\right|_{\Delta t_{\min }=50^{\circ} \mathrm{C}}=1600$ тис.у.о, а оптимальне іï значення $\mathrm{B}_{\text {пр }} \mid \begin{aligned} & \text { опт } \\ & \Delta t_{\min }=22^{\circ} \mathrm{C}\end{aligned}=1200$ тис.у.о.

Цільова функція енергетичних витрат

$$
F \equiv E_{\text {пр }}
$$

має такі значення в крайніх точках області значень $\left.E_{\text {пр }}\right|_{\Delta t_{\min }=10^{\circ} \mathrm{C}}=1592 \kappa \mathrm{BT},\left.\quad E_{\text {пр }}\right|_{\Delta t_{\min }=50^{\circ} \mathrm{C}}=1585 \kappa \mathrm{KT} \quad$ та оптимальне $-E_{\text {пр }} \mid \begin{aligned} & \text { опт } \\ & \Delta t_{\min }=20^{\circ} \mathrm{C}\end{aligned}=1576$ кВт , відповідно. 


\section{ДОПОВНЕННЯ \\ APPLICATION}

Висновки та перспектива подальших досліджень.

Модифікований методу пінч-аналізу, відрізняється від класичного тим, що потокова теплоємність додається до приведених витрат енергії на спорудження і експлуатацію установки первинної переробки нафти методом енергії-нетто. Це дало можливість порівнювати між собою техніко-економічні та енергетичні результати, які отримуються під час аналізу структури установки первинної переробки нафти.

Аналіз параметричної чутливості функції приведених витрат виявив, що при зміні температурного напору як аргумента функції на 20 \%, відбувається ії зміна на 3,1%, при аналогічній зміні вхідної температури первинної сировини - на 2,5 \%, а при зміні кількості теплообмінних апаратів - на 1,7 \%.

В подальшому передбачається знаходження рішення оптимізаційної задачі пошуку оптимальної структури установки первинної переробки нафти різними методами оптимізації з порівнянням отриманих результатів.

\section{Література}

1. Пат. 107027 Україна, МПК C10 G7/00. Установка атмосферної вакуумної трубчатки для підготовки та первинної переробки нафти / Максимов М.В., Кривда В.І.; заявник та патентовласник Максимов М.В., Кривда В.І. - № а201303011; заяв. 11.03.2013; опубл. 10.11.2014, Бюл. № 21/2014. - 5 с.;

2. Ульев Л.М. Пинч-реконструкция секций гидроочистки и каталитического риформинга на установке Л-3511/600 / Л.М. Ульев, Д.Д Нечипоренко // Интегрированные технологии и энергосбережение. - Харьков: НТУ «ХПИ», 2013. - № 2. - С. 95-101.;

3. Foo, D. Minimum Units Targeting and Network Evolution for Batch Heat Exchanger Network / D. Foo, Y. Chew, C. Lee // Applied Thermal Engineering. - 2008. - vol. 28. - №. 16. - P. 2089-2099.;

4. Загорулько Н.Е. Екстракція даних для теплоенергетичної інтеграції процесу концентрації гідролізної сірчаної кислоти / Н.Е. Загорулько, Л.М. Ульєв, А.О. Гарев, Н.В. Нехаєнко // ВІСНИК Національного технічного університету «ХПІ». - 2011. - № 21. - С. 90-97.

References

1. Pat. 107027 Ukraina, MPK C10 G7/00. Ustanovka atmosfernoi vakuumnoi trubchatki dlya pidgotovky ta pervynnoi pererobky nafty [Installation of atmospheric vacuum trubchatka for preparation and primary oil refining] / Maksimov M.V., KryvdaV.I.; zayavnyk ta patentovlasnyk Maksimov M.V., Kryvda V.I. - № a201303011; zayav. 11.03.2013; opubl. 10.11.2014, Byul. № 21/2014. - PP. 5;

2. Ulev L.M. Pinch-rekonstruktsiya sektsiy gidroochistki i kataliticheskogo riforminga na ustanovke L-35- 11/600. L.M. Ulev, D.D Nechiporenko. Integrirovannyie tehnologii i energosberezhenie. - Harkov: NTU «HPI», 2013. № 2. - P. 95-101.;

3. Foo, D. Minimum Units Targeting and Network Evolution for Batch Heat Exchanger Network / D. Foo, Y. Chew, C. Lee // Applied Thermal Engineering. - 2008. - vol. 28. - №. 16. - P. 2089-2099.;

4. Zagorul'ko N.E. Ekstrakcija Danih Dlja Teploenergetichnoï Integraciï Procesu Koncentraciï Gidroliznoï Sirchanoï Kisloti N.E. Zagorul'ko, L.M. Ul'єv, A.O. Garev, N.V. Neha€nko Visnik Nacional'nogo Tehnichnogo Universitetu «Hpi». - 2011. - № 21. - p. 90-97.

\section{СИНТЕЗ ГІБРИДНОЇ МОДЕЛІ АВТОМАТИЗОВАНОГО УПРАВЛІННЯ УЗАГАЛЬНЕНИМ ХОЛОДИЛЬНИМ УСТАТКУВАННЯМ}

Synthesis of hybrid model of automated management of the generalized refrigeration equipment

\section{Селіванова А. В. ${ }^{1}$ (Selivanova A.)}

${ }^{1}$ Одеська національна академія харчових технологій, Одеса

E-mail: av_selivanova@mal.ru ORCID: $\underline{\text { 0000-0002-3395-1422 }}$ 